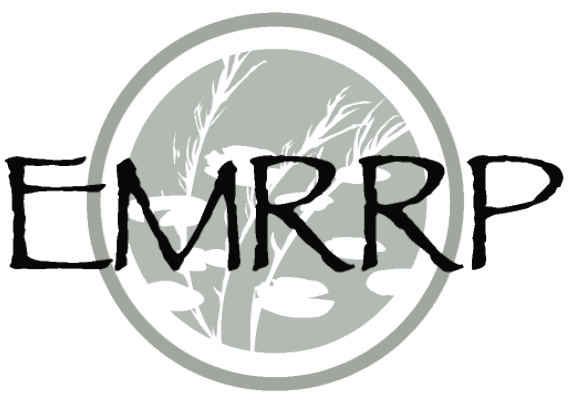

\title{
Retrospective Sustainability and Resilience: Complementary Concepts for Managing Systems
}

\author{
by Katherine F. Chambers ${ }^{1}$, Anne Clark Baker², S. Kyle McKay³,
} and Heather Morgan ${ }^{4}$

\begin{abstract}
No matter the region, locality, or purpose, any given water resource system represents a node within a network of built, natural, and socioeconomic systems. Changes or disturbances to a single node can propagate across these networks of systems, but proper management of disturbances can mitigate impact to a system's performance levels. Effective management of disturbances will be required for the system to persist and function far into the future. Resilience and sustainability are systems management concepts that collectively and holistically address response to disturbance, including the long-term persistence of a system. The goal of this technical note is to compare and clarify the utility and complementarity of the concepts of sustainability and resilience, specifically within the context of the U.S. Army Corps of Engineers (USACE) water resources mission areas. To do so, a brief review and discussion of the relationship between resilience and sustainability systems management concepts is conducted, concluding with the proposal that a combined approach is needed in order to apply both to their greatest effect in the context of water resources management.
\end{abstract}

INTRODUCTION: Water resource systems cannot be separated from the complex built, natural, and socioeconomic networks in which they are embedded. Disturbances to any component of these coupled socio-ecological systems can propagate across these networks, but proper management of disturbances can mitigate impact to a system's performance. Resilience and sustainability are systems management concepts that, together, reflect a system's ability to respond to disturbances, including the long-term function and persistence of a system. However, these concepts can be narrowly defined in practice, with resilience confined to the realm of shortterm response to disturbances, and sustainability to that of "greening" and environmentalism. Such interpretations under-represent not only the full range of the possible types and drivers of disturbances, but also do not account for the full breadth of the concepts of resilience and sustainability, encouraging a dualistic rather than holistic approach to their application.

In addition to the need for a broadened interpretation of resilience and sustainability, central challenges for water managers are the unique temporal and spatial scales associated with the design, construction, and management of water resource systems. In contrast to a single object or building, these systems are shaped by dispersed, and often disconnected, decision making

1 U.S. Army Engineer Research and Development Center (ERDC), Coastal and Hydraulics Laboratory (CHL), Washington, DC, Phone: 202-761-7582, Katherine.F.Touzinsky@usace.army.mil

2 U.S. Army Corps of Engineers (USACE), Institute for Water Resources (IWR), Alexandria, VA, Phone: 703-428-9047, Anne.C.Baker@usace.army.mil

3 ERDC Environmental Laboratory (EL), New York, NY, Phone: 601-415-7160, Kyle.McKay@usace.army.mil

4 AECOM, New York, NY, Phone: 404-964-4539, Heather.Morgan@aecom.com 
processes that may transcend jurisdictional boundaries and require input from a wide range of stakeholders across, within, and adjacent to any given watershed, and sometimes necessitating years or decades for the implementation of design and management decisions.

A BRIEF REVIEW OF SUSTAINABILITY AND RESILIENCE: Prior to examining the complementarity of these concepts, this section reviews the technical foundations of both sustainability and resilience.

Sustainability: The Global, Federal, and USACE Context. Globally, the most common definition of sustainability comes from the United Nations Brundtland Commission report (WCED 1987), which states, "Humanity has the ability to make development sustainable to ensure that it meets the needs of the present without compromising the ability of future generations to meet their own needs." Subsequently, sustainability has often been conceptualized based on a three-pillar or "triple bottom line" model, which proposes a balance of outcomes across issues of economic prosperity, social equity, and ecological health (Pope et al. 2004; General Assembly of the United Nations 2016). This conceptual model is widely applied and referenced across a variety of disciplines and sectors, from local to international contexts, but the relative importance of each pillar remains a focal point of ongoing study and debate, where specific outcomes have been prioritized over others (Jenkins et al 2003; Pope et al. 2004; Gibson 2006). In response to these challenges, principles-based approaches have emerged over the past two decades, emphasizing interconnections and interdependencies among the pillars rather than tradeoffs between them, and encouraging outcomes with multipurpose benefits (Costanza et al. 1998; Pope et al. 2004; Gibson 2006; ODI 2015).

Contemporary applications of the concept of sustainability in the global arena combine a focus on the needs of both current and future generations with a three-pillars approach as a foundation (some applications include a fourth pillar addressing culture) (United Cities and Local Governments 2013), often accompanied by more specific goals or objectives to which a community or group can aspire and move towards. The United Nations' sustainable development definition, identification of the three pillars as its major components, and establishment of seventeen Sustainable Development Goals is an example of such an approach. (General Assembly of the United Nations 2016).

In the United States, the concept of sustainability has been around for a very long time. The Organic Act of 1916, which created the National Park Service, cites the reasons for doing so as a means to leave land unimpaired for future generations. Later legislation, notably the National Environmental Policy Act (NEPA), elaborated on these ideas by introducing the creation and maintenance of conditions "under which human and nature can exist in productive harmony, that permit fulfilling the social, economic and other requirements of present and future generations of Americans" (NEPA 1969). Subsequent $21^{\text {st }}$ century Federal policies adopted this NEPA text as the formal definition of sustainability in the process of setting goals for environmental outcomes, energy use, transportation management, and greenhouse gas emissions (E.O. 13423; E.O. 13514). In 2015, these Executive Orders (EO) were supplanted by the release of E.O. 13693, titled "Planning for Federal Sustainability in the Next Decade," which provides targets for the reduction of greenhouse gas emissions and water use by federal agencies and establishes energy requirements for federal buildings and transportation fleets (CEQ 2015). Notably, this Executive 
Order does not include an explicit definition of sustainability, but remains one of the key references against which Federal agencies currently evaluate sustainability performance.

Building upon these and other legal and policy foundations, the concept of sustainability has been given an increasingly central role in a number of existing USACE policies, practices, and guidance, including three central documents developed over the past fifteen years. First, the USACE Environmental Operating Principles (EOP) were proposed in 2002 as guiding concepts for the integration of environmental practices into all agency actions and decisions (Appendix A), the first EOP is to "foster sustainability as a way of life throughout the organization." Second, the Actions for Change (AFC) Program grew from the recognized need for reform of agency practices following Hurricane Katrina in 2005, and put systems thinking and risk management at the center of agency decision making (Appendix B). Third, the 2014-2018 Civil Works Strategic Plan, Sustainable Solutions to America's Water Resource Needs, articulates a path forward for agency actions in the pursuit of not only sustainable agency practices, but also sustainable water resources (Appendix C). This plan also highlights the need to identify and evaluate water resources management alternatives "from both time (life-cycle) and function (multipurpose) perspectives."

Resilience: USACE and Disciplinary Contexts. Resilience is a property of a system characterizing its response to disturbance and change. This section presents a general overview of key concepts related to understanding and increasing the resilience of USACE systems. Specific and comprehensive reviews on the definitions of resilience are available elsewhere (e.g., Walker and Salt 2006; Wang and Blackmore 2009; Walker et al. 2011; Cutter et al. 2013; Linkov et al. 2014), notably with some disagreement on definitions and use across disciplines and applications (Holling 1973; Hashimoto et al. 1982; Smit et al. 1999; Wang and Blackmore 2009; Marchese et al. 2018).

The USACE, along with many other Federal agencies, has adopted the definition of resilience as, "the ability to anticipate, prepare for, and adapt to changing conditions and withstand, respond to, and recover rapidly from disruptions" (EO 13653). From this definition, the following four concepts emerge to provide a foundation for the assessment and management of system resilience: (1) Prepare (Anticipate), (2) Absorb (Resist), (3) Recover (Bounce Back), and (4) Adapt (Evolve) (Figure 1) (Linkov et al. 2014; Rosati et al. 2015; USACE 2016c).

These four concepts are loosely bound and form the structure around which a large variety of applications exist. Within the USACE, the applications of resilience goals, objectives or principles range from the

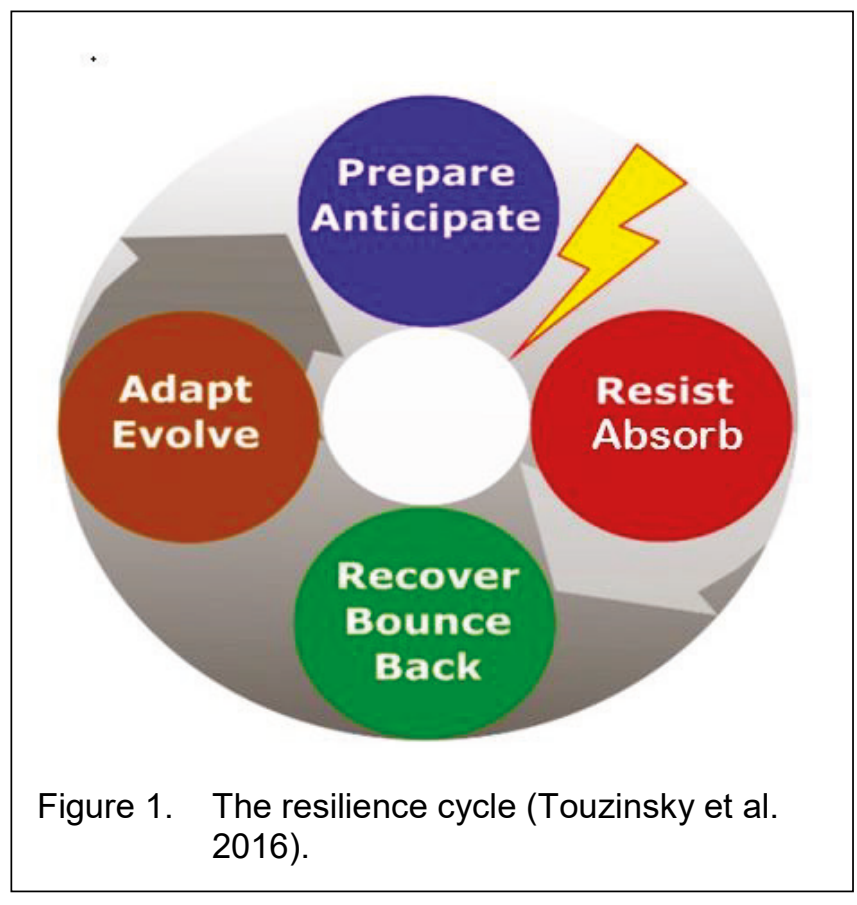


design of flood protection structures, to understanding the reliability of nature-based features, to increasing community risk awareness. For many years, the USACE has integrated the concepts of performance and recovery into its engineered structures, but recent attention on resilience brought about by natural disasters such as Superstorm Sandy has led to a broader incorporation of systems management concepts, response to long-term disasters (e.g., climate change), and adaptive measures following disturbance. The USACE is embracing the concept of resilience with current efforts focused on understanding, quantifying, and managing systems under a variety of potential disturbances (Appendix E).

Before making recommendations for how to manage systems for resilience, it is important to first understand how the concept has evolved within the disciplines of ecology and engineering starting in the 1970s and 1980s. Within the engineering discipline, the concept of resilience was commonly applied to describe the stability of a system near an equilibrium steady state, as measured by the speed at which the system returned to its steady state after a disturbance (Pimm 1984; O'Neil et al. 1986). This measurement of recovery to full performance has been widely accepted across engineering and related disciplines as a means to measure the performance of a system after a stressor, and is further described within several classic papers on the topic (Holling 1996; Liao 2012).

A different interpretation of resilience is rooted in ecological theory, a stressor of an ecological system can push a system into an entirely new operating regime or steady state equilibrium (Holling 1973). This form of resilience is measured by the magnitude of disturbance that the system can absorb before moving to a new equilibrium. For example, a strong hurricane can decimate a maritime forest, increase salt water intrusion, and open the canopy so that the understory is exposed to more salt spray, wind, and sunlight in the coming years (Figure 2). This increase in salinity, sunlight, and temperature pushes the forest towards new steady state equilibrium, a succession of tree growth that selects for a different species composition (Figure 2 bottom) (Conner et al. 2005).

These differences in theory are important to understand, as significant cross-pollination has occurred across engineering, ecology, and related disciplines throughout the evolution of the concept and its applications (e.g., Hashimoto et al. 1982). As the USACE moves beyond defining resilience and towards understanding how the four principles of resilience are applied to systems, it is important to acknowledge this history, so that the system impacts of disturbances are communicated and understood in a consistent manner. 


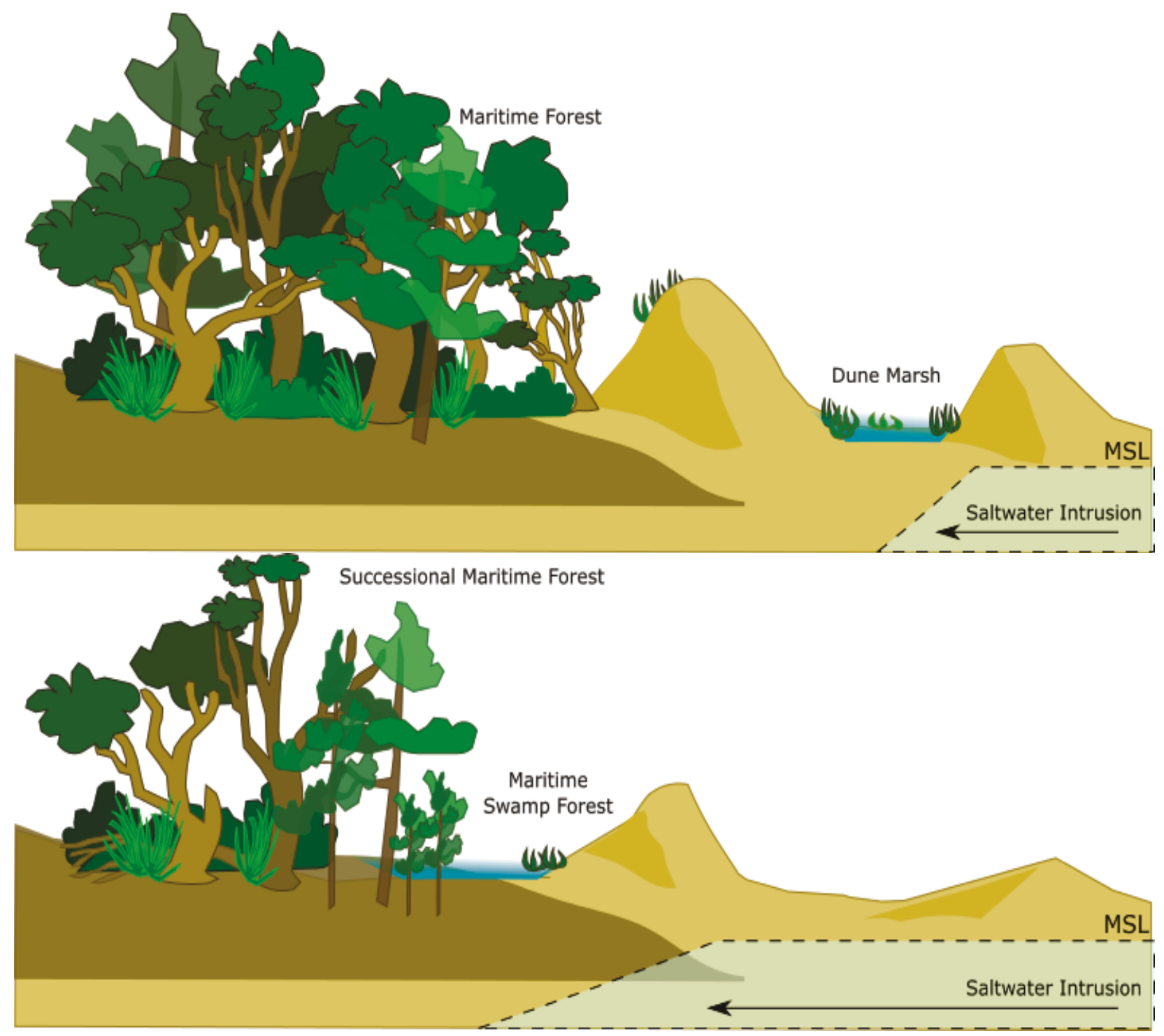

Figure 2. An example of multiple steady state conditions as represented by a maritime forest and dune system before and after a major hurricane event. Top: The pre-storm canopy is dominated by oak and loblolly pine, understory is characterized by palmetto and shrub. The pre-storm dune system has tall fore-dunes, vegetated back dunes and a dune marsh. Dune marshes are intermittent and consist of fresh water lens just above the water table. Bottom: Post-storm, forest species assemblage is dominated by loblolly pine - a highly resilient species.

Decreases in dune height and changes in the water table result in maritime swamp forest.

COMBINING THE CONCEPTS OF SUSTAINABILITY AND RESILIENCE: This technical note explores opportunities to integrate the complimentary concepts of sustainability and resilience to inform decision making and actions focused on the design and management of water resource systems. In order to integrate these concepts, a necessary step is to first clarify the relationship between them. While this technical note does not provide a comprehensive overview of all literature comparing these concepts, it does identify, synthesize, and build upon key ideas drawn from a selection of recent findings (Fiksel 2006; Bochini et al. 2014; Linkov et al. 2014; Redman et al. 2014; Marchese et al. 2018), as outlined in Table 1. 


\begin{tabular}{|l|l||}
\hline \multicolumn{2}{|l||}{ Table 1. A comparison of sustainability and resilience concepts. } \\
\hline \hline Sustainability & Resilience \\
\hline \hline $\begin{array}{l}\text { A sustainable system inherently demonstrates } \\
\text { resilience to disturbances }\end{array}$ & A resilient system is not inherently sustainable \\
\hline $\begin{array}{l}\text { Goals are focused on envisioning a desired future } \\
\text { including long term system health and persistence }\end{array}$ & $\begin{array}{l}\text { Goals are focused on a system's capacity to } \\
\text { address disturbance events }\end{array}$ \\
\hline $\begin{array}{l}\text { Goals, objectives or principles are typically } \\
\text { outcome-focused but also include process-based } \\
\text { actions to address the needs of future generations } \\
\text { (e.g., maintaining reversibility of decisions) }\end{array}$ & $\begin{array}{l}\text { Goals, objectives or principles are largely } \\
\text { process-focused and include short- and long- } \\
\text { term response to disturbance events }\end{array}$ \\
\hline $\begin{array}{l}\text { Prompts consideration of potential tradeoffs } \\
\text { between social, economic and ecological outcomes } \\
\text { with respect to a system's intended function }\end{array}$ & $\begin{array}{l}\text { Prompts consideration of a system's capacity to } \\
\text { prepare, absorb, recover and adapt with respect } \\
\text { to disturbance events }\end{array}$ \\
\hline
\end{tabular}

One manner in which concepts of sustainability and resilience can be compared is through an examination of their relative dependence upon one another (Marchese et al. 2018). As outlined by Redman (2014), resilience is a system characteristic and is an inherent aspect of a sustainable system during the life cycle of a given project. Thus, a sustainable system must demonstrate resilience in order to persist over time, in spite of equilibrium disrupting disturbances. However, resilience may not inherently imply a sustainable system. For instance, a seawall could be designed to increase the resilience of a community to disturbances in the short term, but may not fully consider the social, ecological, and economic costs (e.g., impacts to imperiled species) or the system's resilience over longer time horizons (e.g., sea levels experienced by future generations).

The process of establishing goals, objectives, or principles is a second area where the concepts of sustainability and resilience can be compared and better understood. Resilience is largely a process-driven concept reflecting the ability of a system to minimize the negative effects of destructive events. Conversely, sustainability is primarily a goal-focused concept for maximizing the ability of a system to function over the long-term. From a management context, iterative actions involving the evaluation of system performance and appropriate adaptive management are both required to affect goals focused on the long term health and persistence of a system (Wu 2013; Bocchini et al. 2014).

Aligning Temporal Scales in Decision-Making. The concepts of resilience and sustainability can also be applied to broaden the temporal scales at which systems are analyzed and understood. The concept of sustainability can be applied to expand and even protect opportunities for future decision makers, an approach which requires examining both the past and the future. System performance often depends on past events such as a variety of "legacy effects" or existing inertia within the system (e.g., historical erosion, storm frequencies, reservoir eutrophication, historical relationships among stakeholders). Long-term planning horizons are also important, especially for USACE projects that remain in service far beyond their 50-year period of economic analysis, or 100-year planning horizon. The capacity for these projects to perform with respect to intended functions as defined by both current and future generations will hinge on the capacity to plan for possible outcomes beyond economic and planning horizons. Similarly, resilience requires an understanding of past disturbances and future goals for adaptation, but adds the need for a flexible approach to evaluating the performance of nodes of interest within a system (e.g., the multi-decadal recovery of a maritime forest versus a 72-hour recovery of a community's critical infrastructure). 
Accurately projecting system performance is often a challenge because of uncertainty associated with possible risks, such as climate change (Hallegatte 2008). However, scenario-based and collaborative modeling approaches, life cycle analysis, and the incorporation of risk and resilience considerations into the evaluation of system performance can increase understanding of these uncertainties (Hashimoto 1982; Walker 2003; Sfahani 2015).

\section{Adaptation as Area of Complementarity between Sustainability and Resilience.} Overlaps between sustainability and resilience center around the concept of time, highlighting both short- and long-term adaptation as a key area where the two concepts reinforce one another (Linkov et al. 2014). Considering the functional performance of a home as an example (Figure 3), the importance of adaptation is highlighted here as a key mechanism through which sustainability and resilience can be maximized when considered in an integrated manner reflected in the design and management of a system.

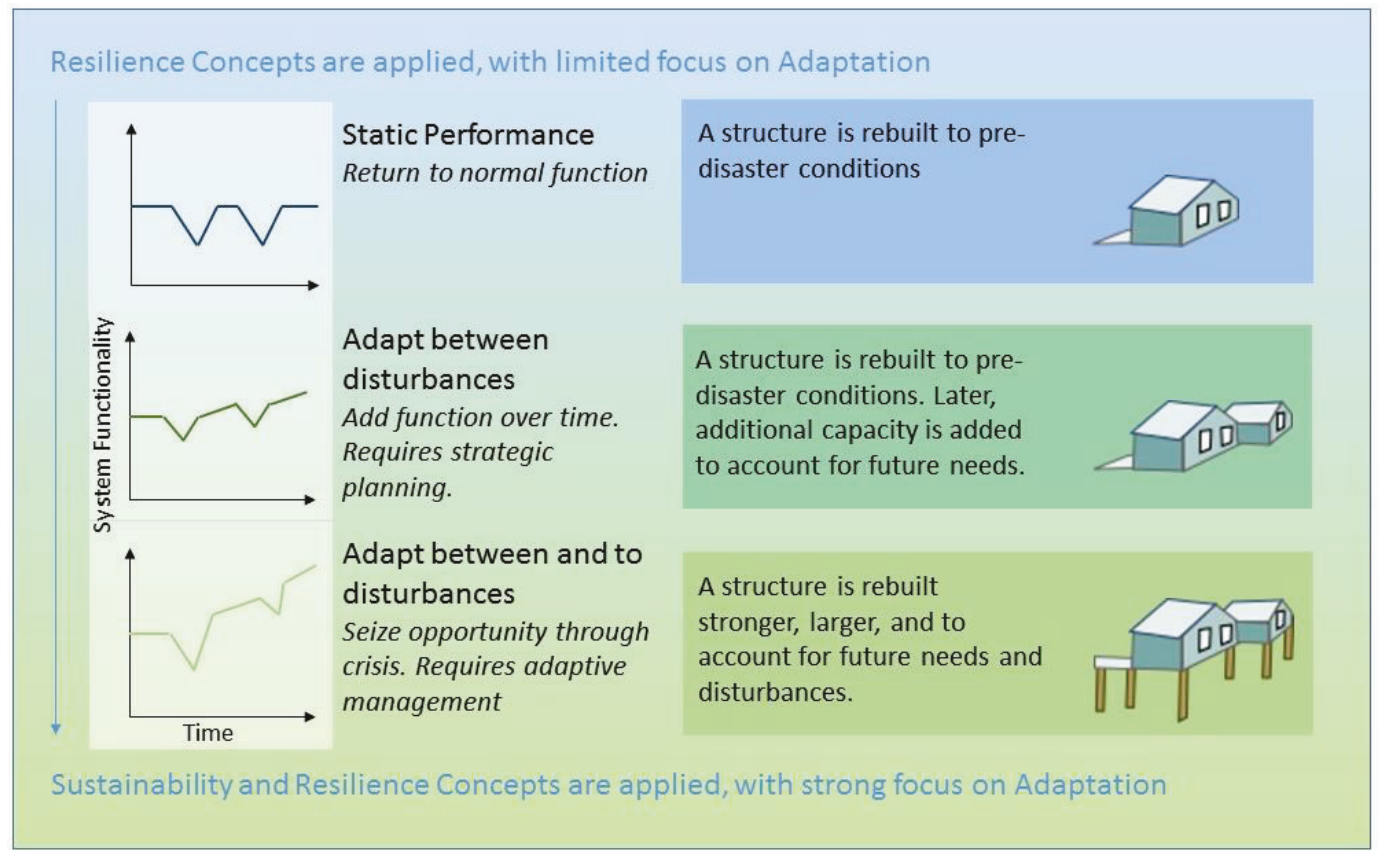

Figure 3. Comparative functionality of a system managed along a spectrum from a limited to strong focus on adaptation.

Without full consideration of the need for adaptation, actions to address a disturbance such as a flood may only account for the effects immediately before and after the event, with a focus on recovering as fast as possible in a return to the previous design standard (Figure 3, Static Performance). If system functionality is increased over time (e.g., by adding additional footage and energy efficiency to accommodate a growing family or home-business), frequent and/or major events can still overwhelm the cumulative benefits of this expanded functionality, particularly if possible disturbance impacts are not accounted for during strategic planning of system improvements (Figure 3, Adapt between Disturbances). Finally, if both concepts of sustainability and resilience are embraced, adaptive management techniques can be employed to bolster the home's ability to recover quickly from a flood event while simultaneously increasing 
functionality and adopting a new structural design of the home in anticipation of future flood conditions (Figure 3, Adapt between and to disturbances).

CONCLUSION: Narrowly defined, resilience to disasters could lead to static performance (or returning to normal function) without the inclusion of sustainable practices such as strategic planning and adaptive management. Narrowly defined, system sustainability could be compromised without the inclusion of resilience practices such as adapting between and to disturbances. Adaptation provides a key area of complementarity between sustainability and resilience. A combined framework for applying these two concepts can help guide design and management decisions for systems that both functionally adapt to achieve long-term goals, and rebound stronger after setbacks and disturbances (i.e., bounce forward).

This technical note has sought to review and compare the concepts of sustainability and resilience in the context of the USACE mission. Both concepts are grounded in a rich body of academic literature across a wide variety of disciplines. However, practical, management-oriented applications and policies emphasizing these concepts are still in early stages of development.

A review of literature comparing the two concepts suggests that their integrated application to decision making for systems design and management can increase the likelihood that economic, social and ecological outcomes are balanced over short and long planning horizons as well as ensure system function is maintained during disturbances. The comparative analysis provided in this paper is intended to serve as a starting point for an evolving, adaptive approach to integrating both sustainability and resilience as complementary concepts into water resources systems management in the future.

ADDITIONAL INFORMATION: This technical note was published by the Ecosystem Management and Restoration Research Program (EMRRP). The USACE Proponent for the EMRRP Program is Ms. Mindy Simmons and the Technical Director is Dr. Al Cofrancesco. The broad scope of this work required and benefited enormously from input by a number of colleagues, including but not limited to: Dr. Todd Bridges, Brian Harper, Kendall Zaborowski, Matthew Bates, and Megan Burke. This publication was peer-reviewed by Christian Manalo and Dr. Michael Guilfoyle.

For additional information, contact Katherine Touzinsky (202-761-7582, Katherine.F.Touzinsky @ usace.army.mil), or the manager of the Ecosystem Management and Restoration Research Program, Dr. Trudy Estes (601-634-2125, Trudy.J.Estes@usace.army.mil). This technical note should be cited as follows:

Touzinsky K. F., A. C. Baker, S. K. McKay, and H. Morgan. 2019. Sustainability and Resilience: Complementary Concepts for Managing Systems. EMRRP Technical Notes Collection. ERDC/TN EMRRP-SR-86. Vicksburg, Mississippi: U.S. Army Engineer Research and Development Center. http://cwenvironment.usace.army.mil/eba/. 


\section{REFERENCES}

Bocchini, P., D. Frangopol, T. Ummenhofer, and T. Zinke. 2014. Resilience and sustainability of civil infrastructure: Toward a unified approach. Journal of Infrastructure Systems doi: 10.1061./(ASCE)IS.1943-555X.0000177.

Council on Environmental Quality (CEQ). 2015. The White House, Office of Federal Sustainability, June 10, 2015. Implementing Instructions of Federal Executive Order 13693, Planning for Federal Sustainability in the Next Decade. (Accessed on 1 November 2018). https://www.wbdg.org/FFC/FED/EO/eo13693 instructions.pdf. https://obamawhitehouse.archives.gov/administration/eop/ceq/initiatives/sustainability

Council on Environmental Quality (CEQ). 2015. The White House, Federal Leadership on Climate Change and Environmental Sustainability - Executive Order 13693, February 19, 2015. (Accessed on 1 November 2018). https://www.whitehouse.gov/administration/eop/ceq/sustainability

Conner, W. H., W. D. Mixon II, and G. W. Wood. 2005. Maritime forest habitat dynamics on Bulls Island, Cape Romain National Widlife Refuge, SC, following Hurricane Hugo. Forest Ecology and Management 212(1-3):127-134. https://doi.org/10.1016/j.foreco.2005.03.008.

Costanza, R., F. Andrade, P. Antunes, M. van den Belt, D. Boersma, D. F. Boesch, F. Catarino, S. Hanna, K. Limburg, B. Low, M. Molitor, J. G. Pereira, S. Rayner, R. Santos, J. Wilson, and M. Young. 1998. Principles for sustainable governance of the oceans. Science 281(5374):198-199. doi: 10.1126/science.281.5374.198.

Cutter, S. L., J. A. Ahearn, B. Amadei, P. Crawford, E. A. Eide, G. E. Galloway, M. F. Goodchild, H. C. Kunreuther, M. Li-Vollmer, M. Schoch-Spana, S. C. Scrimshaw, E. M. Stanley, G. Whitney, and M. L. Zoback. 2013. Disaster resilience: A national imperative. Environment: Science and Policy for Sustainable Development 55(2):25-29. https://doi.org/10.1080/00139157.2013.768076.

Durden, S. E., and M. Wegner-Johnson. 2013. Other Social Effects: A Primer. 2013-R-02 Institute for Water Resources. Vicksburg, MS: U.S. Army Corps of Engineers (USACE). http://www.iwr.usace.army.mil/ Portals/70/docs/iwrreports/2013-R-02.pdf.

Fiksel, J. 2006. Sustainability and resilience: toward a systems approach. Sustainability: Science, Practice, and Policy. 2(2):14-21. https://doi.org/10.1080/15487733.2006.11907980.

Folke, C., S. R. Carpenter, B. Walker, M. Schefer, T. Chapin, and J. Rockstrom. 2010. Resilience thinking: Integrating resilience, adaptability, and transformability. Ecology and Society 15(4):20-29. https://www.jstor.org/ stable/26268226

General Assembly of the United Nations, President of the 65th Session, 2016. Sustainable Development. http://un.org/en/ga/president/65/issues/sustdev.shtml.

Gibson, R. B. 2006. Beyond the pillars: Sustainability assessment as a framework for effective integration of social, economic and ecological considerations in significant decision-making. Journal of Environmental Assessment Policy and Management 8(3):259-280. https://doi.org/10.1142/S1464333206002517.

Gunderson, L. H. 1999. Stepping Back: Assessing for Understanding in Complex Regional Systems. In 'Bioregional Assessments: Science at the Crossroads of Management and Policy. Eds. K. N. Johnson, F. Swanson, M. Herring and S. Green, 27-40. Washington, DC: Island Press.

Gunderson, L. H., C. S. Holling, and S. S. Light. 1995. Barriers and Bridges to Renewal of Ecosystems and Institutions. New York: Columbia University Press.

Hallegatte, S. 2009. Strategies to adapt to an uncertain climate change. Global Environmental Change 19(2):240-247. doi:10.1016/j.gloenvcha.2008.12.003.

Hashimoto, T., J. R. Stedinger, and P. Loucks. 1982. Reliability, resiliency, vulnerability criteria for water resource system performance evaluation. Water Resources Research 18(1):14-20. https://doi.org/10.1029/WR018i001p00014.

Holling, C. S. 1973. Resilience and stability of ecological systems. Annual Review of Ecology and Systematics 4:1-23. https://doi.org/10.1146/annurev.es.04.110173.000245. 
Holling, C. S. 1986. The Resilience of Terrestrial Ecosystems: Local Surprise and Global Change. 292-317. Eds W. C. Clark and R. E. Munn. In Sustainable Development of the Biosphere. Cambridge, Ma: Cambridge University Press.

Holling, C. S. 1996. Engineering Resilience versus Ecological Resilience. In Engineering within Ecological Constraints. P.C. Schulze, Washington, DC: National Academy Press. 31-43.

Holling, C. S. 2001. Understanding the complexity of economic, ecological, and social systems. Ecosystems 4(5):390-405. https://doi.org/10.1007/s10021-001-0101-5.

Jenkins, B., D. Annandale, and A. Morrison-Saunders. 2003. Evolution of a sustainability assessment strategy for Western Australia. Environmental Planning Law Journal 201(1):56-65.

Levin, S. A. 1998. Ecosystems and the biosphere as complex adaptive systems. Ecosystems 1(5):431-436.

Liao, K. H. 2012. A theory on urban resilience to floods- a basis for alternative planning practices. Ecology and Society 17(4). http://dx.doi.org/10.5751/ES-05231-170448.

Linkov I., T. Bridges, F. Creutzig, J. Decker, C. Fox-Lent, W. Kröger, J. H. Lambert, A. Levermann, B. Montreuil, J. Nathwani, R. Nyer, O. Renn, B. Scharte, A. Scheffler, M. Schreurs, and T. Thiel-Clemen. 2014. Changing the resilience paradigm. Nature Climate Change 4(6):407-409.

Marchese D., E. Reynolds, M. E. Bates, H. Morgan, S. S. Clark, and I. Linkov. 2018. Resilience and sustainability: Similarities and differences in environmental management applications. Science of the Total Environment 613-641:1275-1283. doi: 10.1016/j.scitotenv.2017.09.086.

National Academy of Engineering. 1996. Engineering Within Ecological Constraints. Washington, DC: The National Academies Press. doi:10.17226/4919.

Overseas Development Institute. (ODI) 2015. Exploring Spaces for economic transformation in the Sustainable Development Goals. (Accessed on 31 October 2018). https://www.odi.org/sites/odi.org.uk/files/odiassets/publications-opinion-files/9651.pdf.

Ogden, J. C., S. M. Davis, K. M. Jacobs, T. Barnes, and H. Fling. 2005. The use of conceptual ecological models to guide ecosystem restoration in south Florida. Wetlands 25(4):795-809.

O’Neill, R. V., D. L. DeAngelis, J. B. Waide, and T. F. H. Allen. 1986. A Hierarchical Concept of Ecosystems. Princeton, NJ: Princeton University Press.

Pimm, S. L. 1984. The Balance of Nature. Chicago, IL: University of Chicago Press.

Pope, J., D. Annandale, and A. Morrisson-Saunders. 2004. Conceptualizing sustainability assessment. Environmental Impact Assessment Review 24(6):595-616. https://doi.org/10.1016/j.eiar.2004.03.001.

Redman, C. L. 2014. Should sustainability and resilience be combined or remain distinct pursuits? Ecology and Society 19(2). doi: 10.5751/ES-06390-190237.

Union of Concerned Scientists (UCS). 2016. The U.S. Military on the Front Lines of Rising Seas. (Accessed on 31 October 2018). http://www.ucsusa.org/global-warming/global-warming-impacts/sea-level-rise-flooding-usmilitary-bases\#.V-w5OBGa3vW.

United Cities and Local Governments. 2013. Culture: The Fourth Pillar of Sustainable Development. (Accessed on 1 Oct 2018). http://www.agenda21 culture.net/sites/default/files/files/documents/en/zz_culture4pillarsd_eng.pdf.

U.S. Army Corps of Engineers (USACE). 2014. Global Changes: Procedures to Evaluate Sea Level Change: Impacts, Responses and Adaptation. ETL 1100-2-1 Technical Letter. Vicksburg, MS: U.S. Army Corps of Engineers (USACE).

U.S. Army Corps of Engineers (USACE) Department of the Army. 2006. U.S. Army Corps of Engineers (USACE) Releases of Statement on USACE 12 Actions for Change. (Accessed on 1 November 2018). https://www.pnwa.net/new/Articles/12\%20Actions\%20for\%20Change.pdf.

U.S. Army Corps of Engineers (USACE) Institute for Water Resources. 2009. National Economic Development Procedures Manual Overview. (Accessed 1 November 2018). http://corpsnedmanuals.us. 
U.S. Army Corps of Engineers (USACE). 2012. Environmental Operating Principles. (Accessed on 1 November 2018). https://www.usace.army.mil/Missions/Environmental/Environmental-Operating-Principles/.

U.S. Army Corps of Engineers (USACE). 2014. Sustainable Solutions To America's Water Resource Needs: Civil Works Strategic Plan 2014-2018. (Accessed on 31 October 2018). https://www.usace.army.mil/portals/2/docs/ civilworks/news/2014-18 cw stratplan.pdf.

U.S. Army Corps of Engineers (USACE). 2015. Program Level Adaptive Management Plan, Comprehensive Everglades Restoration Plan. https://usace.contentdm.oclc.org/digital/collection/p16021coll7/id/8184/.

United Nations Sustainable Development Goals. 2016. (Accessed on 31 October 2018). http://sustainabledevelopment.un.org.

Walker, J., and M. Cooper. 2011. Genealogies of resilience from systems ecology to the political economy of crisis adaptation. Security Dialogue 42(2):143-160. https://doi.org/10.1177/0967010611399616.

Walker B. and D. Salt. 2006. Resilience Thinking: Sustaining Ecosystems and People in a Changing World. Washington, D.C: Island Press.

World Commission on Environment and Development. 1987. Our Common Future, From One Earth to One World, A/42/427. (Accessed on 1 November 2018). http://www.un-documents.net/ocf-ov.htm; A/42/427. 


\section{APPENDIX A}

USACE Environmental Operating Principles (USACE; Bostick 2012):

1. Foster sustainability as a way of life throughout the organization.

2. Proactively consider environmental consequences of all USACE activities and act accordingly.

3. Create mutually supporting economic and environmentally sustainable solutions.

4. Continue to meet our corporate responsibility and accountability under the law for activities undertaken by the USACE which may impact human and natural environments.

5. Consider the environment in employing a risk management and systems approach throughout life cycles of projects and programs.

6. Leverage scientific, economic, and social knowledge to understand the environmental context and effects of USACE actions in a collaborative manner.

7. Employ an open, transparent process that respects views of individuals and groups interested in USACE activities.

\section{APPENDIX B}

USACE Actions for Change (USACE; Strock 2006):

Effectively Implement a Comprehensive Systems Approach: Comprehensively design, construct, maintain and update engineered systems to be more robust, with full stakeholder participation.

1. Employ integrated, comprehensive and systems-based approach.

2. Employ risk-based concepts in planning, design, construction, operations, and major maintenance.

3. Continuously reassess and update policy for program development, planning guidance, design and construction standards.

4. Employ dynamic independent review.

5. Employ adaptive planning and engineering systems

6. Focus on sustainability.

7. Review and inspect completed works.

8. Assess and modify organizational behavior.

Communication: Effective and transparent communication with the public, and within the USACE, about risk and reliability.

1. Effectively communicate risk.

2. Establish public involvement risk reduction strategies.

Reliable Public Service Professionalism: Improve the state of the art and the USACE dedication to a competent, capable workforce on a continuing basis. Make the commitment to being a "learning organization" a reality.

1. Manage and enhance technical expertise and professionalism.

2. Invest in research. 


\section{APPENDIX C}

USACE Civil Works Strategic Plan 2014-2018 (USACE 2014):

Vision: Contribute to the strength of the Nation through innovative and environmentally sustainable solutions to the Nation's water resources challenges.

Mission: Serve the public by providing the Nation with quality and responsive: Development and management of the Nation's water resources; Support of commercial navigation; Restoration, protection and management of aquatic ecosystems; Flood risk management; and Engineering and technical services in an environmentally sustainable, economic, and technically sound manner with a focus on public safety and collaborative partnerships.

Goals: How We Accomplish Our Mission

1. Transform the Civil Works Program to deliver sustainable water resources solutions through Integrated Water Resources Management.

2. Improve the safety and resilience of communities and water resources infrastructure.

3. Facilitate the transportation of commerce goods on the Nation's coastal channels and inland waterways.

4. Restore, protect, and manage aquatic ecosystems to benefit the Nation.

5. Manage the life-cycle of water resources infrastructure systems in order to consistently deliver sustainable services

\section{Achieving the Goals:}

These goals and strategies will help respond to the myriad of challenges facing the Civil Works Program. Goal 1 captures the transformational initiatives that address the current and future water resources needs of the Nation. Goal 2 includes the concepts of safety and resilience, and the intent to reduce economic and human life losses from floods. Goal 3 addresses the USACE navigation program, which provides safe, reliable, highly costeffective, and environmentally sustainable waterborne transportation systems for the movement of commercial goods. Goal 4 focuses on restoring aquatic habitat to a more natural condition in those ecosystems whose structures, functions, and dynamic processes have become degraded. Goal 5 emphasizes adaptive operation and management of existing USACE projects throughout their life cycle. Reliability is also an element of this goal, and reflects the implementation of risk-based asset management in the area of operations and maintenance of USACE infrastructure.

\section{Overarching Strategy:}

Integrated Water Resources Management (IWRM) is a holistic focus on water resource challenges and opportunities that reflects coordinated development and management of water and related resources. IWRM considers economic benefits, ecosystem quality and health and public safety. These factors are considered in project formulation. 


\section{Cross-cutting strategies:}

Systems Approach - Water resources planning and management should use systems analysis methods and tools to understand, assess, and model the interconnected nature of hydrologic systems (e.g., watersheds) and the economic and ecologic systems they support, and to identify and evaluate management alternatives from both time (life-cycle) and function (multipurpose) perspectives. Collaboration and Partnering - Build and sustain collaboration and partnerships at all levels to leverage authorities, funding, talent, data, and research from multiple agencies and organizations.

Risk-Informed Decision Making and Communication - Develop and employ risk and reliability-based approaches that incorporate consequence analysis, especially risk to life; identify, evaluate, and forestall possible failure mechanisms; and quantify and communicate residual risk.

Innovative Financing - Explore innovative financing arrangements such as public-private partnerships to develop and sustain the Nation's water resources infrastructure.

Adaptive Management - Adaptive management is a decision process that promotes flexible decision making that can be adjusted in the face of risks and uncertainties - such as those presented by climate change-as outcomes from management actions and other events become better understood through monitoring and improved knowledge.

State-of-the-Art Technology - Embrace new and emerging technology for its fullest advantage. Invest in research that improves the resiliency of structures, assists in updating design criteria, and improves approaches toward planning and design.

\section{APPENDIX D}

ETL 1100-2-1, Technical Letter. Global Changes: Procedures to Evaluate Sea Level Change: Impacts, Responses and Adaptation, Section 2 (Department of the Army 2014):

"Longer Planning Horizon. The planning, design, and construction of a large water resources infrastructure project can take decades. Though initially justified over a 50-year economic period of analysis, USACE projects can remain in service much longer. The climate for which the project was designed can change over the full lifetime of a project to the extent that stability, maintenance, and operation may be impacted, possibly with serious consequences, but also potentially with beneficial consequences. Given these factors, the project planning horizon (not to be confused with the economic period of analysis) should be 100 years, consistent with ER 1110-2-8159."

\section{APPENDIX E}

The USACE Resilience Initiative

The U.S. Army Corps of Engineers (USACE) Resilience Initiative (the Initiative) was created in 2015 with the goal of evolving and further enhancing resilience throughout 
USACE diverse mission sets. Currently, over 75 USACE staff from across the agency are participating in the Initiative, helping to develop its priorities and meet its objectives.

http://www.usace.army.mil/Missions/Sustainability/Building-Resilience/

Coastal Resilience Research and Development

In the fall of 2013, Lieutenant General (LTG) Thomas Bostick (RET) charged the Coastal Engineering Research Board (CERB), a board of civilian experts and military officials, to develop a "strategy to integrate risk and resilience into USACE practices" (Rosati et al. 2015). The research team assembled by the CERB recommended a tiered approach to assessing resilience that incorporates flexibility in planning stage, level of time, effort, and data intensity. Currently, ERDC is engaged in a Coastal Systems Resilience Initiative joint funded by the three ERDC business lines (Flood Risk Management, Environmental, and Navigation).

Climate Preparedness and Resilience Community of Practice

The mission of the Responses to Climate Change Program is to develop, implement, and assess adjustments or changes in operations and decision environments to enhance resilience or reduce vulnerability of USACE projects, systems, and programs to observed or expected changes in climate.

http://www.corpsclimate.us/

NOTE: The contents of this technical note are not to be used for advertising, publication, or promotional purposes. Citation of trade names does not constitute an official endorsement or approval of the use of such products. 